\author{
Professor Masoud RABBANI, PhD \\ E-mail: mrabani@ut.ac.ir(Corresponding author) \\ School of Industrial Engineering, College of Engineering \\ University of Tehran, Tehran, Iran \\ Sahar ZAHEDIFARD, MSc \\ E-mail: s.zahedifard@ut.ac.ir \\ School of Industrial Engineering, College of Engineering \\ University of Tehran, Tehran, Iran \\ Mohammad REZAEI-MALEK, PhD Candidate \\ E-mail: m.rezaeimalek@ut.ac.ir \\ School of Industrial Engineering, College of Engineering \\ University of Tehran, Tehran, Iran
}

\title{
AN INTEGRATED MULTI-CRITERIA DECISION-MAKING APPROACH FOR PORTFOLIO PROBLEM IN ENERGY SERVICE COMPANIES UNDER UNCERTAINTY
}

Abstract. Energy and its surrounding issues have become major problems around the world for decades and leading to a global concern about efficient energy use. Energy Service Companies (ESCOs) play a significant role in energy saving projects. Regarding various practicable financial mechanisms and potential customers, selection of profitable projects and proper financial mechanisms is vital for the ESCOS. This paper is carried out in two stages. The first stage comprises a mathematical model to find the optimum set of projects to be accepted by an ESCO. The presented model has two objectives, including minimization of risk and maximization of benefit. According to the business of the ESCOs, three major financial mechanisms are considered including internal, debt and leasing financing. Hence, the second stage involve ranking these financial mechanisms by an integrated AHP-fuzzy PROMETHEE method, in order to finance the selected optimal bundle of projects, which are obtained at the first stage.

Keywords: ESCO, Portfolio Problem, Bi-objective Optimization, Fuzzy PROMETHEE, Uncertainty.

JEL Classification: D81, C61, 013

\section{Introduction}

In recent years, population increase and economic growth in all over the world have dramatically raised the energy demand. The environmental pollution, exhaustion of energy resources, and fluctuation of energy market prices (from the early 1970s) have threaten human life at every level. Hence, the governments tend

DOI: $10.24818 / 18423264 / 52.4 .18 .20$ 
to concentrate on developing policies, regulations, and incentives to increase efficient energy use in different major sectors such as industry, public, etc.

Energy Service Companies (ESCOs) play a significant role in the Energy Efficiency (EE) projects. An ESCO typically provide its customers with energy audits, development, design, financing, installation, operation, monitoring and maintenance services, which are performed under energy performance contracting (EPC) agreements. EPC utilizes generated bill savings in order to repay the project operation, maintenance, and investment costs during project life that is guaranteed by an ESCO, itself. One of the most important benefits of an EPC is that all costs are paid by EE improvement savings. Therefore, the energy cost savings must cover total project costs in order to be economically reasonable. However, ESCO's projects seem to be risky and are sometimes too small to attract the attention of large financial institutions. Legal and regulatory frameworks are also not fully supportive toward ESCO's investment and financial institutions conservatively deal with them (Vine, 2005). Therefore, selection of rational profitable projects is necessary for supporting and developing the ESCOs.

Due to specific characteristics of energy performance projects, there are various financing mechanisms for facility owners and ESCO managers. Several sources can provide the capital for ESCO's projects that is accessible by a range of various financing alternatives. Based on Houlihan (2008), there are four main financing mechanisms for an ESCO under EPC agreement, including internal financing, debt financing, leasing financing and utility incentives. Elaboration on financial mechanisms and providing the customers with better methods or combinatory ones facilitate the development of ESCOs. Although several supportive measures and policies referring energy efficiency have been implemented in many countries, there is a need for looking into the issue of reliable and optimum performance of ESCOs about financing more precisely.

Vine et al. (1998) developed cultural and financial barriers and presented guidance for the development of ESCO industry in Japan. Afterward, Vine et al. (1999) surveyed the evolution of US ESCO industry and focused on the interaction between utilities and super ESCOs. To be specific, the types of services and products that super ESCOs will be presenting in the future were developed. Goldman et al. (2005) presented their observations in which performance contracting overcomes market barriers for energy efficiency investments among large, institutional and public sector for US ESCOs. Okay et al. (2008) presented their viewpoints regarding the funding and related risks that the forthcoming Turkish ESCO market can be faced with. Marino (2010) introduced professionals and policy makers, and provided comprehensive information about barriers and success factors, identified trends of ESCO development across EU member states over the period of 2007 to 2010. Okay and Akman (2010) used a pre-surveyed database on the sectors targeted by ESCOs in 38 countries. The database included the number of ESCO companies (NE), age of ESCO market (AEM), and total value of ESCO projects (VE) in each country. They illustrated dependencies 
An Integrated Multi-Criteria Decision-Making Approach for Portfolio Problem in Energy Service Companies under Uncertainty

between the ESCO indicators (EI) (i.e. AEM, NE, VE, and sectors targeted by ESCOs) and the country indicators (CI) (i.e. global innovation index (GII) and percapita gross domestic production (GDP), energy consumption (EC) and CO2 emission). Marino et al. (2011) presented a comprehensive insight of the European ESCO industry based on the results obtained from a large-scale survey performed in 39 European countries in 2009-2010. They described the observed market development (during 2007-2010), factors influencing the ESCO evolution, and trends in business practices. They presented barriers, supporting factors, useful policy measures, and the successful experiences about ESCO activities in Europe. Limaye and Limaye (2011) presented barriers to the development of a viable ESCO industry in developing countries. They introduced super ESCO as a means of facilitating large scale implementation of EE projects.

It seems that there is a need to develop a method in order to choose an optimal and profitable set of projects among the proposed ones to an ESCO. Fernández and Gómez (2007) applied artificial neural networks in order to solve the general mean-variance portfolio selection model and trace out its efficient frontier. Moreover, a new multi-objective particle swarm was designed to select the optimal energy supply systems, considering environmental, economic, social and technical parameters by Zakernia et al. (2010). To do that, they used an integrated mathematical model using linear programming and three multi-criteria approaches including Analytic Hierarchy Process (AHP), Technique for Order Preference by Similarity to Ideal Solution (TOPSIS) and Elimination and Choice Expressing Reality III (ELECTRE III). The economic and qualitative attribute under budget constraints was proposed by (Siqueira de souza et al., 2012), whereby traditional methods of investment analysis was integrated with multi-criteria analysis methods.

In addition, elaboration on financial mechanisms and providing the customers with better methods can facilitate the development of ESCOs. Notably, using a combination of financing mechanisms may lead to a better performance and consequently a higher profit for both sides. Therefore, there is a challenge to select a suitable financial mechanism for funding the selected bundle of projects. As financial problems involve qualitative and quantitative criteria, multi attribute decision making (MADM) methods are more popular in this regard.

According to the above review, the project selection problem for an ESCO has not been studied yet. There is also no mathematical model in the scope of ESCO activities. Hence, this paper aims to propose a mathematical model in order to select an optimal and profitable bundle of projects for an ESCO, in the first stage. This model considers two objectives simultaneously: (1) minimizing the risk and (2) maximizing the profit of the selected projects. Due to the project's uncertain nature i.e. the economic fluctuation, the model is considered under 
Masoud Rabbani, Sahar Zahedifard, Mohammad Rezaei-Malek

uncertain environment by a scenario-based approach. While ESCO financial mechanisms are one of the most important parts of implementing its projects, there are also a few studies on related financial issues. Therefore, in the second stage, a fuzzy multi attribute approach for ranking financial mechanisms is presented. Based on Yilmaz and Dagdeviren (2011), in comparison with other MCDM methods, PROMETHEE also facilitates the conceptions and application of various assumptions and information. As the input data may be associated with some uncertainties, an extension of PROMETHEE under fuzzy environment is applied in this paper. Thus, an AHP-fuzzy PROMETHEE methodology is proposed to rank the financial mechanisms for a typical ESCO. Amongseveral important criteria in economic problems, four criteria are considered in this study. The AHP method is used to obtain the weighing vector and the Fuzzy-PROMETHEE method is then applied to rank the financial mechanisms.

\section{Problem Description}

Generally, ESCOs face a wide range of proposed projects to work in them, but as mentioned in the literature review section different projects have different conditions; therefore, in an ESCO the decision maker should select the best projects with regards to the different considerations; profit, derived saving, requirement resources and limitation on available amount of them, credit constraint of projects, and risk. In addition, the ESCO should consider the plausible changes in the criteria value (e.g., value of risk, credit, derived saving, and cost) according to the probable scenarios that are related to our uncertain real world. The project selection should be done based on two goals; minimization of risk and maximization of profit. Once the suitable projects are selected, to finance the selected projects there are different methods of financing in the ESCO industry namely Internal, Debt, and Leasing method. Based on Vine et al. (1998), Vine (2005), Goldman et al. (2005), Okay et al. (2008), Mario (2010), Mario et al. (2011), and Limaye and Limaye (2011), some economic and cultural criteria (qualitative and quantitative) are required to be defined for making a conscious decision on different financial mechanisms. Considering the nature of economic problem and the necessity for satisfying some of vital indices for ESCOs, i.e. economic, cultural and policy making, the decision-making to select the proper finance method should be made with considering qualitative criteria including lack of awareness and information (LAI) and supportive policies (SP) and quantitative criteria including risk and profit. Due to the uncertain nature of economic conditions, the profit is considered as a triangular fuzzy number. Based on expert's opinion the criteria are weighted through the AHP method. Afterwards, a full ranking vector for three afore-mentioned financial mechanisms is computed using the fuzzy-PROMETHEE method on a case study. For convenient of reader, the schematic representation of the problem is as follows (see Figure 1): 
An Integrated Multi-Criteria Decision-Making Approach for Portfolio Problem in Energy Service Companies under Uncertainty

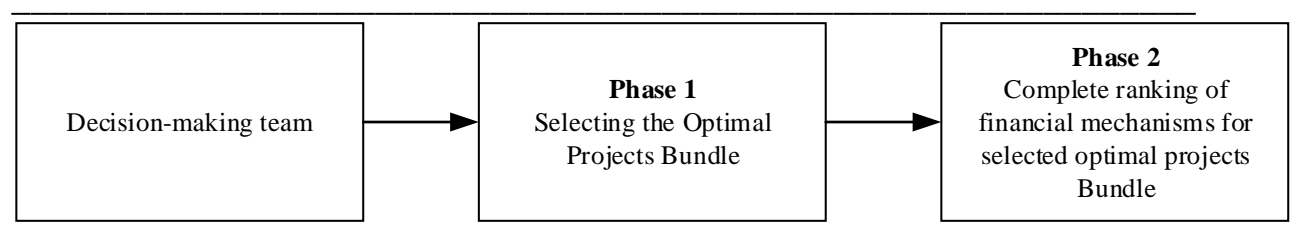

Figure 1. Schematic representation of the problem

\section{Methodology}

\subsection{Stage One: Selecting the Optimal Projects}

\subsubsection{Constructing Mathematical Model}

The mathematical model for project selection by the ESCO is elaborated in this section. First, the following assumptions are considered for the problem:

Assumptions:

- Duration of proposed projects is greater than a certain amount (five years) that is defined by decision-maker (DM),

- Saving of proposed projects is greater than costs,

- There is no interdependency among the projects,

- There is a limitation for number of selected projects.

Indices:

$i \quad$ index of proposed projects $(i=1, \ldots, I)$,

$j \quad$ index of resource types $(j=1, \ldots, J)$,

$s \quad$ index of scenarios $(s=1, \ldots, S)$.

Parameters:

$p_{s}$ probability of occurrence of scenario $s$,

$r_{i s} \quad$ risk of project $i$ under scenario $s$,

$u_{i s} \quad$ credit of project $i$ under scenario $s$,

$b_{i s}$ derived saving from implementing project $i$ under scenario $s$,

$M_{j} \quad$ total amount of resource type $j$,

$m_{i j}$ amount of resource type $j$ for project $i$,

$c_{i s}$ cost of project $i$ under scenario $s$,

$U$ expected credit mean of each project,

$K$ minimum number of selected projects.

Decision variables:

$x_{i} \quad 1$; if project $i$ is selected, 0 ; otherwise,

$D_{i s}$ difference between saving and cost of project $i$ under scenario $s$. 


$$
\begin{aligned}
& \text { Model formulation: } \\
& \operatorname{Max} Z_{1}=\sum_{i=1}^{I} \sum_{s=1}^{S} D_{i s} \\
& \operatorname{Min} Z_{2}=\sum_{i=1}^{I} \sum_{s=1}^{S} p_{s} r_{i s} x_{i} \\
& \text { s.t. } \\
& \sum_{i=1}^{I} m_{i j} x_{i} \leq M_{j} \quad \forall j=\{1, \ldots, J\} \\
& \sum_{i=1}^{I} u_{i s} x_{i} \geq U \sum_{i} x_{i} \quad \forall s=\{1, \ldots, S\} \\
& \left(b_{i s}-c_{i s}\right) x_{i} \geq D_{i s} \quad \forall i=\{1, \ldots, I\}, s=\{1, \ldots, S\} \\
& \sum_{i} x_{i} \geq K \\
& x_{i}=\text { binary variable and } D_{i s} \geq 0
\end{aligned}
$$

Objective function (1) maximizes the sum of difference between the saving and cost of selected projects under all scenarios. Objective function (2) minimizes the risk of selected projects in all scenarios. Equation (3) ensures that needed resources for each project are prepared by the ESCO. In addition, the credit of each project (i.e. customer) is a critical criterion for selecting projects, because it is important for an ESCO to ensure the success of projects and the customer's ability of affording the projects. Equation (4) shows that the credit of selected projects has to be more than the DM's expected credit for each project. The difference between saving and cost of each project is maximized in objective function (1) as shown in Equation (5). Equation (6) shows that at least $K$ projects should be selected, and the last one, constraint (7) expresses the non-negativity constraints.

\subsubsection{Selection of an Appropriate MOP Technique}

Considering the bi-objective mathematical model and the necessity of interactive relations with decision maker (DM) in the decision-making process (selecting the optimal projects bundle), interactive MOP methods are more suitable than the other MOP methods. One of these methods is Reservation Level Tchebycheff Procedure (RLTP). The RLTP method uses the systematic mechanism for reducing non-dominated solution till it achieves the most preferred solutions for DM. This method applies reservation levels $(R L s)$ based upon DM's opinion to reduce the objective space. Like the RLTP method, the $\varepsilon$-constraint method also uses $R L s$ to solve MOPs. Hence, the RLTP and $\varepsilon$-constraint methods are applied in the portfolio problem to select the Optimal Projects Bundle. This paper suggests 
An Integrated Multi-Criteria Decision-Making Approach for Portfolio Problem in Energy Service Companies under Uncertainty

the RLTP and $\varepsilon$-constraint methods for two main reasons as follows (Reeves and Macleod, 1999):

- The need for an interactive MOP method (necessity of using the DM's preferences; reservation levels),

- Its efficiency considering the non-convex nature of the problem because of presence of binary variables.

The RLTP method can be described in terms of four steps as follows (Reeves and Macleod, 1999):

\section{Initialization}

I.1. Determine the number of solutions, $N$ to be presented to the DM at each iteration, where $N \geq P$, and $P$ is the number of objective functions.

I.2. Compute a reference objective vector $\left(y^{u}\right)$, by solving $P$ single objective problems (see Equation (8)) to use in solving the Tchebycheff program in Step 3.

$$
y^{u}=\left(y_{1}^{u}, y_{2}^{u}, \ldots, y_{P}^{u}\right): y_{k}^{u}=\min \left\{f_{k}(x) ; x \in X\right\}-\varepsilon_{k} \quad \forall k=1 \text { to } P
$$

where $\varepsilon_{k}$ are small positive scalars used in the solution procedure of Tchebycheff program.

I.3. Set $\mathrm{RL}_{k}=+\infty$ for $k=1, \ldots, P$.

I.4. Specify the maximum number of iterations.

\section{Sampling}

With utilizing the formulation (9), generate a group of $2 N$ dispersed weight vectors (Steuer and Choo, 1983; Steuer, 1986).

$$
\Lambda=\left\{\lambda \in R^{P} \mid \lambda_{k} \in(0,1), \sum_{k=1}^{P} \lambda_{k}=1\right\}
$$

\section{Solution}

In this step, solve the associated Tchebycheff program (10-13) for each weighted vector $\lambda$ that is generated in Step 2 .

$$
\begin{aligned}
& \min \left\{\alpha-\rho \sum_{k=1}^{P} f_{k}(x)\right\} \\
& \text { s.t. } \\
& \quad x \in X \\
& \quad \alpha \geq \lambda_{k}\left(f_{k}(x)-y_{k}^{u}\right) \quad \forall k=1, \ldots, P \\
& \quad f_{k}(x) \leq \mathrm{RL}_{k} \quad \forall k=1, \ldots, P
\end{aligned}
$$


Masoud Rabbani, Sahar Zahedifard, Mohammad Rezaei-Malek

According to Steuer and Choo (1983), $\rho$ is a small positive scalar suggested to be between 0.0001 and 0.01 .

Present the $N$ maximally dispersed solutions to the DM using the method presented in (Steuer and Choo, 1983; Steuer, 1986). If the DM decides to continue to search for a better solution, proceed to Step 4. Otherwise, the DM selects the most his/her preferred solution and stop.

\section{Adjustment}

In this step and Step 3 of final iteration, the DM participates more actively on interactive way to adjust RLs. According to the DM's considerations, the current solutions should be divided to more and less preferred subset, adjust RLs and return to Step 2.There are two points for adjusting RLs: (1) RLs for each $k$ must be set worse than or equal to the worst value for that objective among the current more preferred solutions, (2) at least one RL must be set better than an objective value of a current less preferred solution. If the DM accepts, the RLs can be adjusted automatically by RLTP rather than by the DM (see Equation (14)):

$\mathrm{RL}_{k}=\mathrm{MPWV}_{k}-r\left(\mathrm{MPWV}_{k}-\mathrm{CSWV}_{k}\right)$

Where:

$\mathrm{CSWV}_{k}$ : The worst value over the set of all current solutions,

$\mathrm{MPWV}_{k}$ : The worst value over the subset of more preferred current solutions,

$r$ : Reduction factor between 0 and 1(smaller values for $r$ correspond to faster rates of objective space reduction).

Haimes et al. (1971) introduced $\varepsilon$-constraint method. In this method, one of the objective functions is chosen to be optimized and the other objectives are converted to constraints. These constraints have upper bound $\left(\varepsilon_{i}\right)$ that can be assumed $R L_{i}$ values (Demirtas and Üstün 2008). The form of problem in $\varepsilon$ constraint is as follows (Sedighy et al., 2015):

$\operatorname{Min} f_{j}(x)$

s.t. $\quad f_{i}(x) \leq \varepsilon_{i} \quad$ For all $i=1,2 ; \quad i \neq j \quad\left(\varepsilon_{i}=R L_{i}\right)$

\subsection{Stage Two: MCDM Method to Rank the Financial Mechanisms for Optimal Projects Bundle}

It is assumed that for ESCO projects there is a certain arrangement of services (design, installation or construction of $\mathrm{EE}$ and facility upgrades) with a constant price for all mechanisms. This assumption can facilitate the computations. Following information is considered in the financial computations for each mechanism:

Internal Financing: Internal financing is one of the most direct and administratively simplest financial mechanisms. The following items are considered from the internal financing balance sheet: 
An Integrated Multi-Criteria Decision-Making Approach for Portfolio Problem in Energy Service Companies under Uncertainty

- Costs

$\circ$ Operating costs

○ Direct costs

$\circ$ Initial cost (pre-construction costs)

- Revenue (EE savings)

- Depreciation (for properties and equipment)

- Tax savings

Debt Financing: It is more complex than internal financing. Almost all large projects can be handled by this mechanism as it involves less risk to the ESCOs. Therefore, there are three involved agents including the ESCO, financial institution and the facility. In addition to items mentioned for previous mechanisms, the following items are also associated with this mechanism:

- Tax on interest payment as another factor of tax savings

- Annual payment for loan repayment

Leasing Financing: One of the major advantages of leasing agreement is that there are abilities to reduce or eliminate the consideration of up-front capital costs for new energy efficient equipment. There are five types of leasing including finance lease, operating lease, non-leveraged lease and service lease. Since finance lease has lower risk and can repay the lessor investment with high profitability, it is considered as the chosen leasing method in this paper. In common leasing methods in economy, there are two sides (lessee and lessor). In here; there is another side between lessee and lessor which is ESCO with an important role in leasing contracts. It is assumed that ESCO guarantees leasing payments such that at the beginning of every year it pays $\% 10$ of leasing payment from energy efficiency savings. If the savings were less than leasing payment ESCO is responsible to pay for the difference. The following item is added to those mentioned in the internal mechanism:

- Guarantee expense

The above financial factors are used in the second stage of the computations, in order to calculate the quantitative criteria i.e. the profit and the risk within the MCDM approach.

\subsubsection{AHP}

The AHP as a decision-making tool was firstly proposed by Saaty (1980). It is especially advantageous with respect to its simplicity in use and ability to decompose a complex problem including tangible and intangible factors into its constituent parts (Turcksina et al., 2011). Overall objective, criteria and the considered alternatives are at least three levels of a hierarchy. The objective is at 
highest level of the hierarchy, criteria and sub-criteria are at the lower levels. Comparing all the elements of the lower level against the higher criteria determines the relative priorities of each element in the hierarchy.

Weights can be calculated by normalizing any of rows or columns in the pair-wise comparison matrix. The full elaboration of the AHP method can be found in Saaty (1980).

\subsubsection{Fuzzy PROMETHEE}

The PROMETHEE is one of the most appropriate MCDM techniques that can yield the full ranking of alternatives. First, the alternatives are evaluated by different criteria, and then a definite preference function $\left(p_{j}(a, b)\right)$ should be defined ranging from 0 to $1 . p_{j}(a, b)$ is a non-decreasing function of the obtained deviation (d) between the scores of the alternatives using the considered criterion $\left(f_{j}(a)-f_{j}(b)\right)$, as shown in Formula 15.

$$
P_{j}(a, b)=G_{j}\left\{f_{j}(a)-f_{j}(b)\right\}
$$

This paper applies the linear function as the selected preference function among six possible shapes. As the overall preference index, $\Pi(a, b)$ is computed based on the positive $\varphi^{+}(a)$ and negative $\varphi^{-}(a)$ preference flows, which measures how an alternative $(a)$ is outranking (see Formula 17) or outranked (see Formula 18 ) by the other alternatives. Then difference between these preference flows is represented as the net preference flow $\varphi(a)$ (see Formula 19), whereby a higher value reflects a higher attractiveness of alternative $a$ (Turcksina et al., 2011).

$$
\begin{aligned}
& \pi(a, b)=\sum_{j=1}^{k} w_{j} P_{j}(a, b) \\
& \varphi^{+}(a)=\frac{1}{n-1} \sum_{b} \pi(a, b) \\
& \varphi^{-}(a)=\frac{1}{n-1} \sum_{b} \pi(b, a) \\
& \varphi(a)=\varphi^{+}(a)-\varphi^{-}(a)
\end{aligned}
$$

Finally, the higher the net flow for an alternative, the superior is the alternative in the final ranking. In this paper, the Fuzzy-PROMETHEE method is proposed, like that proposed by Yilmaz and Dagdeviren (2011). All the computations and operations of the PROMETHEE method are undertaken with the fuzzy numbers while the preference threshold ( $p$ and $q$ ) and criteria weights are crisp numbers. In this paper, a fuzzy number is presented in the form of $x=\left(a_{1}, a_{2}\right.$, $a_{3}$ ), which is based on Lee (2005) and $a_{2}$ is the mean value. In order to conduct the related computations, it is required to know about the basic knowledge of fuzzy numbers and their operations (Yilmaz and Dagdeviren, 2011). The difference between the performance of (A) and (B) actions $(d)$ is expressed by a fuzzy number $(a, b, c)$, so we have: 
An Integrated Multi-Criteria Decision-Making Approach for Portfolio Problem in Energy Service Companies under Uncertainty

$$
\left\{\begin{aligned}
P(a, b)=0, & a \leq q \\
p(a, b)=\frac{d-q}{p-q}, & q \leq a \text { and } c \leq p \\
p(a, b)=1, & c \geq p
\end{aligned}\right.
$$

In the last step, fuzzy net preference flow needs to be diffuzied and compared to gain the full ranking. The proposed ranking method is as it was by $\mathrm{Li}$ and $\mathrm{Li}$ (2010). First a fuzzy function as below is defined for a fuzzy number $\tilde{A}=[a, b, c]$ as $d f(\tilde{A})=\frac{a+b+c}{n}$. The spread $\mathrm{STD}_{A}$ is determined as follows $\operatorname{STD}_{A}=\sqrt{\frac{(\mathrm{a}-\operatorname{df}(\tilde{A}))^{2}+(\mathrm{b}-\operatorname{df}(\tilde{A}))^{2}+(\mathrm{c}-\operatorname{df}(\tilde{A}))^{2}}{n-1}}$. Also, the score $\tilde{A}$ for each fuzzy number $\tilde{A}$ is: $\operatorname{Score}(\tilde{A})=d f(\tilde{A}) \times\left(1-\lambda \cdot S T D_{A}\right)$

Parameter $\lambda \in\{0.5,1.5\}$ is for the importance degree of the spreads. If the spread is more important, the $\lambda=1.5$ is set, otherwise it is 0.5 .

Measurement is a major challenge in implementing consumer engagement initiatives and a main reason why offline companies are reluctant in considering this approach. However, the development of technology has proven to be an exceedingly important instrument for creating, maintaining and enhancing consumer engagement. Specifically, there is an increasing number of online companies that offer customer relationship management online software and applications that make the measurement of consumer engagement an easily accomplishable aspect form companies looking to explore the benefits of this concept. Marketing managers are enthusiastic about consumer engagement; however, they have difficulty in implementing this construct due to their perceived lack of quantitative metrics. To overcome these perceived challenges, any consumer engagement indicator should be clear and relevant to the business context and outcomes. Firstly, in terms of the metric being clear, it must be easily understood by everyone from within and outside the company. Secondly, the relevant or specific nature of the metric implies a connection to business performance, goals and outcome. Gallup's (2009) research has shown that many popular metrics - like Customer Satisfaction, Customer Loyalty, and Advocacy (including Net Promoter) — do not consistently demonstrate strong links to key business outcomes. Thus, this research aims to provide valuable insights on available consumer engagement metrics and their applicability.

\section{Numerical Experiment: An Actual Case Study}

Due to the quite high financial risk of ESCOs in the world, the applied approach in this paper can deal with some financial risks of ESCO's business 
Masoud Rabbani, Sahar Zahedifard, Mohammad Rezaei-Malek

process. This paper considered two critical steps of the main decision for a typical ESCO that is the selection of optimum project bundle and then suitable financial method for them. In this section, a simplified real-life example is expressed using an ESCO data in Iran. This approach can assist other similar companies having the mentioned assumptions and conditions to decrease the financial risk and increase their profit.

\subsection{Phase One: Project Selection by Mathematical Model}

In order to show the applicability of the proposed model and solution method, RLTP, $\varepsilon$-constraint and Weighted Sum Method (WSM)are coded in GAMS and solved using the case study data (see Table 1). The mathematical model is solved by the GAMS23.5.2/CPLEX12.2solver.

Table 1. The Scenario-based data of the projects

\begin{tabular}{|c|c|c|c|c|c|}
\hline Project & Scenario & Credit & $\begin{array}{c}\text { Derived } \\
\text { Saving }\end{array}$ & Cost & Risk \\
\hline \multirow{3}{*}{1} & 1 & 44 & 100 & 25 & 43 \\
\hline & 2 & 60 & 125 & 33 & 49 \\
\hline & 3 & 70 & 135 & 45 & 53 \\
\hline \multirow{3}{*}{2} & 1 & 80 & 200 & 75 & 85 \\
\hline & 2 & 75 & 175 & 42 & 80 \\
\hline & 3 & 77 & 188 & 60 & 83 \\
\hline \multirow{3}{*}{3} & 1 & 95 & 345 & 102 & 100 \\
\hline & 2 & 89 & 320 & 88 & 80 \\
\hline & 3 & 77 & 250 & 112 & 75 \\
\hline \multirow{3}{*}{4} & 1 & 75 & 225 & 49 & 90 \\
\hline & 2 & 60 & 187 & 39 & 85 \\
\hline & 3 & 85 & 250 & 65 & 95 \\
\hline \multirow{3}{*}{5} & 1 & 59 & 151 & 25 & 75 \\
\hline & 2 & 55 & 142 & 42 & 70 \\
\hline & 3 & 50 & 123 & 33 & 65 \\
\hline \multirow{3}{*}{6} & 1 & 42 & 98 & 19 & 65 \\
\hline & 2 & 30 & 65 & 17 & 55 \\
\hline & 3 & 33 & 73 & 28 & 60 \\
\hline \multirow{3}{*}{7} & 1 & 65 & 170 & 24 & 80 \\
\hline & 2 & 55 & 155 & 19 & 75 \\
\hline & 3 & 44 & 139 & 15 & 70 \\
\hline \multirow{3}{*}{8} & 1 & 78 & 250 & 50 & 75 \\
\hline & 2 & 70 & 210 & 33 & 85 \\
\hline & 3 & 98 & 350 & 60 & 100 \\
\hline \multirow{2}{*}{9} & 1 & 45 & 102 & 22 & 67 \\
\hline & 2 & 42 & 95 & 18 & 60 \\
\hline
\end{tabular}


An Integrated Multi-Criteria Decision-Making Approach for Portfolio Problem in Energy Service Companies under Uncertainty

\begin{tabular}{llllll}
\hline & 3 & 50 & 127 & 29 & 73 \\
\multirow{4}{*}{10} & 1 & 57 & 145 & 37 & 70 \\
& 2 & 59 & 122 & 28 & 63 \\
& 3 & 70 & 161 & 39 & 77 \\
\hline
\end{tabular}

\subsubsection{Reservation Level Tchebycheff Procedure (RLTP)}

In this method, it is decided to present three solutions to DM at each iteration and the $\rho=0.0001$ is used in Step 3 based on Reeves and MacLeod (1999). Then, the single objective problems are solved. The payoff table is shown in Table 2. The maximum value of each objective function from the payoff table is used for an initial value of each $\mathrm{RL}_{k}$.

Table 2. Payoff table

\begin{tabular}{lcc}
\hline The optimal solution for single objective model & $z_{1}$ & $z_{2}$ \\
\hline$x_{1}^{*}=$ optimal solution for $z_{1}$ & 3772.000 & 796.100 \\
$x_{2}^{*}=$ optimal solution for $z_{2}$ & 1816.000 & 376.800 \\
$y_{k}^{I}=$ Ideal value & 3772.000 & 376.800 \\
$y_{k}^{N}=$ Approximate Nadir Value & 1816.000 & 796.100 \\
\hline
\end{tabular}

In the second step, 6 dispersed weight vectors are generated randomly (Steuer, 1986), and are solved the AWTP (Augmented Weighted Tchebycheff Procedure) model for each. The results are shown in Table 3.

Table 3. Weight vectors and the value of objectives obtained from the AWTP

\begin{tabular}{ccccccc}
\hline & $1^{*}$ & 2 & 3 & 4 & $5^{*}$ & $6^{*}$ \\
\hline$\lambda_{1}$ & 0.31 & 0.43 & 0.50 & 0.64 & 0.75 & 0.11 \\
$\lambda_{2}$ & 0.69 & 0.57 & 0.50 & 0.36 & 0.25 & 0.89 \\
\hline$z_{1}$ & 3132.000 & 3313.614 & 3424.100 & 3536.144 & 3632.233 & 2542.000 \\
$z_{2}$ & 656.200 & 722.600 & 724.700 & 796.100 & 796.100 & 528.800 \\
\hline
\end{tabular}

The solutions marked with * show maximally dispersed solutions obtained by applying the filtering method proposed by Steuer and Choo (1983). If the DM is satisfied with these results, he/she must select his/her current most preferred solution and stop. Suppose that the DM wishes to continue searching for an improved solution and selects Solution 1 as most preferred solutions. If DM is not tightened, RLs get tightened automatically at each iteration by using Formula 14 . The new values of RLs are computed as follows: 
Masoud Rabbani, Sahar Zahedifard, Mohammad Rezaei-Malek

RL1 $=-2542.000-0.2(-2542.000+1816.000)=-2868.8$

RL2 $=796.100-0.2(796.100-796.100)=796.100$

The most DM's preferred solution of iteration 2 with considering new RLs is the same as the most preferred solution of iteration 1. The final solution for $Z_{1}$ and $Z_{2}$ was 3132.000 and 656.200 respectively, having the time of $0.015 \mathrm{~s}$.

Suppose that the DM is satisfied with the present solution (In other conditions if the DM is not satisfied, the AWTP must be solved with the new RLs again.). Regarding objectives and data of the case study, it is reasonable that a set of projects (i.e. 1, 2, 3, 4, 7 and 8) is selected. As it is highly more beneficial for ESCOs to have large projects rather than small ones, the industry and public sector would be an appropriate place in order to invest in and accept relevant projects. In addition, there is considerable interaction between the condition of industry and government's macroeconomic policies. In several countries i.e. Bulgaria, Egypt, Kenya, Philippines, Thailand, and Ukraine, a large amount of ESCO activities belongs to the industrial sector (Okay et al., 2008).

\subsubsection{The E-constraint Method}

When the first objective is restricted by the DM, the objectives of the mathematical model can be converted into the following form so that the objective function will be $\left\{\right.$ Min $\left.z_{2}\right\}$ and the initial objective function will be as a constraint as follows: $\mathrm{z}_{1} \leq \varepsilon_{1}\left(\varepsilon_{1}=R L_{1}=-2868.8\right)$. The results show that the bundle of projects that minimizes the total value of the risk are projects number 5,8 and 10 with objective functions $\mathrm{z}_{1}=2902.000$ and $\mathrm{z}_{2}=611.200$. It should be considered that low profit does not make this solution preferable to the DM.

\subsubsection{Comparative Analysis}

To compare the quality of final solutions obtained by RLTP, $\varepsilon$-constraint and weighting methods, an additive function $(U(z))$ with weights 0.5 and 0.5 was applied. The results are shown in Table 4.Table 5 shows the solution qualities for three different methods with eight different combinations of weights via the additive utility function. According to the results (Table 5), RLTP outperforms the other methods in our problem.

Table 4. The final solutions obtained by using RLTP, $\varepsilon$-constraint and WSM

\begin{tabular}{ccccc}
\hline & $z_{1}$ & $z_{2}$ & $U(z)$ & $t$ (in s) \\
\cline { 2 - 5 } RLTP & 3132.000 & 656.200 & 1894.1 & 0.015 \\
$\varepsilon$-constraint & 2902.000 & 611.200 & 1756.6 & 0.015 \\
WSM & 1816.000 & 376.800 & 1096.4 & 0.00001 \\
\hline
\end{tabular}


An Integrated Multi-Criteria Decision-Making Approach for Portfolio Problem in Energy Service Companies under Uncertainty

Table 5. The solution quantities for three different methods via additive utility function with different weights

\begin{tabular}{cccccc}
\hline \multirow{2}{*}{ Weights } & & \multicolumn{3}{c}{$U(Z)$} & \\
\cline { 3 - 5 } 0.1 & 0.9 & RLTP & $\varepsilon$-constraint & WM & Max $U(z)$ \\
\cline { 3 - 5 } 0.35 & 0.65 & 1522.73 & 1412.98 & 520.72 & 903.78 \\
0.7 & 0.3 & 2389.26 & 2214.76 & 1384.24 & 1522.73 \\
0.45 & 0.55 & 1770.31 & 1642.06 & 1024.44 & 1770.31 \\
0.8 & 0.2 & 2636.84 & 2443.84 & 1528.16 & 2636.84 \\
0.5 & 0.5 & 1894.1 & 1756.6 & 1096.4 & 1894.1 \\
\hline
\end{tabular}

\subsection{Phase Two: Ranking the Financial Mechanisms for Selected \\ Optimal Projects Bundle}

\subsubsection{Applying AHP and Fuzzy PROMETHEE}

The problem will be evaluated according to data given in Table 6 . The pair-wise comparison matrix of the main criteria with respect to the goal yields the weight of criteria (Table 7). The applied normalization method was based on the geometric mean.

Table 6. Alternatives and attributes for financial mechanism selection

\begin{tabular}{ccccc}
\hline Alternatives & LAI & Profit $\left(10^{6} \$ / \mathrm{yr}\right)$ & Risk & SP \\
\hline Internal & 2 & $(14.33,16.33,19.2)$ & 10.04 & 3 \\
Debt & 5 & $(7.72,8.72,10,6)$ & 11.26 & 8 \\
Leasing & 7 & $(20.20,22.69,25.69)$ & 6.96 & 5 \\
\hline
\end{tabular}

Table 7. Criteria weights

\begin{tabular}{ccccc}
\hline \multirow{3}{*}{ Weight } & LAI & Profit & Risk & SP \\
\cline { 2 - 5 } & 0.089 & 0.554 & 0.196 & 0.16 \\
\hline
\end{tabular}

Based on the AHP procedure, the criteria are weighted to be used as the inputs in the Fuzzy PROMETHEE method. In the last step of PROMETHEE, fuzzy net preference flow needs to be diffuzified and compared to gain a full ranking. The proposed ranking method is as it was by $\mathrm{Li}$ and $\mathrm{Li}$ (2010). As the last step, the alternatives should be written in a descending order of their net flow in crisp form $(\mathrm{Q}(1)=-0.04, \mathrm{Q}(2)=-0.12, \mathrm{Q}(3)=0.17)$, therefore, the complete ranking is $\mathrm{Q}(3)$, $\mathrm{Q}(1), \mathrm{Q}(2)$.This shows that the leasing mechanism is preferred to internal mechanism, and subsequently internal mechanism is preferred to the debt financing for a typical ESCO based on data of case study. 


\subsubsection{Sensitivity Analysis}

The last step involves investigating the effect of criteria weights on the ranking of three alternatives including internal financing, debt financing and leasing. It was assumed that each weight is increased by 0.25 and its impact was observed on the final ranking (Büyüközkan and Çifçi, 2012). The results are shown in Figure 2.

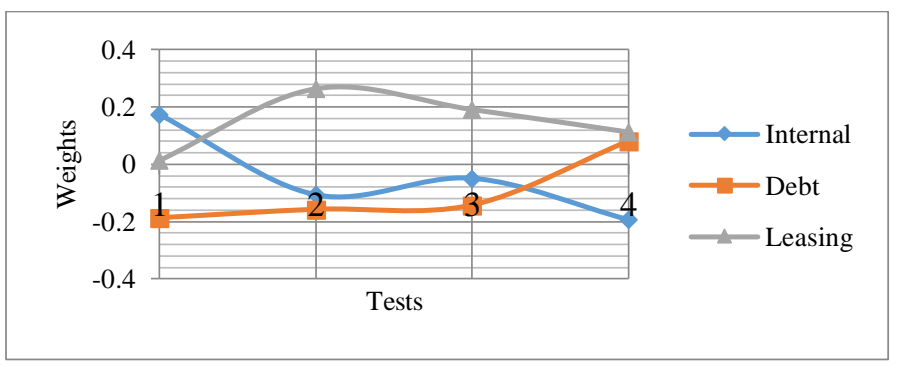

Figure 2. Performance sensitivity of alternatives

Inhere the weights of criteria are changed separately one by one, considering that the total weights equal to 1 . Sensitivity analysis shows that the increase of the weight does not change the ranking except in two cases. When the weight of risk is increased, internal financing is ranked first. This indicates that leasing mechanism is sensitive to lack of awareness that means when a greater importance is attached to awareness; internal financing is placed in first priority. Moreover, adopting larger weight for supportive policy shows that debt financing is ranked higher than internal, although leasing is still in top priority.

\section{Conclusion}

The energy service company (ESCO) concept has been emerged first in the early 1980s. The ESCO typically provides its customers with energy auditing, developing, designing, financing, installation, operation and maintenance services, which are performed under energy performance contracting (EPC) agreements. In this paper, a combined approach for selecting financial mechanisms of accepted projects has been proposed. First, a bi-objective mathematical model has been proposed to select a set of optimal projects. The model is based on occurrence of three scenarios with different probabilities. Then, using four qualitative and quantitative criteria through the AHP method and decision maker's opinion the weight of criteria have been gained and applied as the initial weighting vector in the fuzzy PROMETHEE II methodology. Due to variable economic situation, the profit criterion has been considered as a triangular fuzzy number. At the end, the fuzzy net flows of the PROMETHEE method have been deffuzied. According to case study assumptions, it is shown that among the financial mechanisms, leasing is the most appropriate one followed by internal and debt financing. It should be 
An Integrated Multi-Criteria Decision-Making Approach for Portfolio Problem in Energy Service Companies under Uncertainty

noted that the applied procedure in this paper is just for an instant ESCO. In order to make it more general, additional assumptions can be considered into the model. This study may help decision makers as a basic guide when faced with same problems, in which the ESCO needs to find the optimal set of projects and select the most suitable financial mechanisms for them.

For future researches, interdependency among projects, and some other criteria can be considered in MADM methods. The corresponding computational time grows exponentially with the problem size. Therefore, in order to solve the real-sized problems, developing appropriate meta-heuristic methods is of great importance.

\section{REFERENCES}

[1] Büyüközkan, G. and Çifçi, G. (2012), A Combined Fuzzy AHP and Fuzzy TOPSIS Based Strategic Analysis of Electronic Service Quality in Healthcare Industry. Expert Systems with Applications, 39(3), 2341-2354;

[2] Demirtas, E.A., and Üstün, Ö. (2008), An Integrated Multi-Objective Decision Making Process for Supplier Selection and Order Allocation. Omega, 36(1), 76-90;

[3] Fernández, A. and Gómez, S. (2007), Portfolio Selection Using Neural Networks. Computers and Operations Research, 34(4), 1177-1191;

[4] Goldman, C.A., Hopper, N.C. and Osborn, J.G. (2005), Review of US ESCO Industry Market Trends: An Empirical Analysis of Project Data. Energy Policy, 33(3), 387-405;

[5] Haimes, Y.Y., Wismer, D.A. andLasdon, D.S. (1971), On a Bi-Criterion Formulation of the Problems of Integrated System Identification and System Optimization. IEEE Transactions on Systems, Man and Cybernetics, 1(3), 296297;

[6] Houlihan, A. (2008), Financing Energy Efficiency Improvements: Practice Guide \#21. Southeast Regional Environmental Finance Centre. University of Louisville;

[7] Lee, K.H. (2005), First Course on Fuzzy Theory and Applications. SpringerVerlag;

[8] Limaye, D. and Limaye, E. (2011), Scaling up Energy Efficiency: The Case for a Super ESCO. Energy Efficiency, 4(2), 133-144;

[9] Li, W. and Li, B. (2010), An Extension of the PROMETHEE-II Method Based on Generalized Fuzzy Numbers. Expert Systems with Applications, 37(7), 5314-5319;

[10] Marino, A. (2010), Energy Service Companies Market in Europe. Luxembourg: Status Report 2010. Publications office of the European Union; 
Masoud Rabbani, Sahar Zahedifard, Mohammad Rezaei-Malek

[11] Marino, A.,Bertoldi, P., Rezessy, S. and Boza-Kiss, B. (2011), A Snapshot of the European Energy Service Market in 2010 and Policy Recommendations to Foster a Further Market Development. Energy Policy, 39(10), 6190-6198;

[12] Okay, E., Okay, N., Konukman, A. and Akman, U. (2008),Views on Turkey's Impending ESCO Market: Is It Promising? Energy Policy, 36(6), 1821-1825;

[13] Okay, N. and Akman, U. (2010), Analysis of ESCO Activities Using Country Indicators. Renewable and Sustainable Energy Reviews, 14(9), 2760-2771;

[14] Reeves, G.R. and MacLeod, K.R. (1999), Some Experiments in TchebycheffBased Approaches for Interactive Multiple Objective Decision Making. Computers and Operations Research, 26(13), 1311-1321;

[15] Saaty, T.L. (1980), The Analytic Hierarchy Process: Planning, Priority Setting, and Resource Allocation. McGraw-Hill International Book Co.;

[16] Sedighy, S.Q., Shakouri, H. and Rezaei-Malek, M. (2015), A Novel MultiObjective Mathematical Model for Planning an Auxiliary Public Transportation Network: A Covering-Routing Approach. Economic Computation and Economic Cybernetics Studies and Research, 49(1), 239-262;

[17] Steuer, R. (1986), Multiple Criteria Optimization. Wiley, New York;

[18] Steuer, R.E. and Choo, E.U. (1983), An Interactive Weighted Tchebycheff Procedure for Multiple Objective Programming. Mathematical Programming, 26, 326-44;

[19] Siqueira de souza, J., Kliemann neto, J., Filomena, T., Anzanello, M. (2012), A Non-traditional Capital Investment Criteria-Based Method to Optimize a Portfolio of Investments. International Journal of Industrial Engineering: Theory, Applications and Practice, 19(4);

[20] Turcksina, L., Bernardinia, A. and Macharisa, C. (2011), A combined AHPPROMETHEE Approach for Selecting the most Appropriate Policy Scenario to Stimulate a Clean Vehicle Fleet. Procedia Social and Behavioral Sciences, 20, 954-965;

[21] Vine, E. (2005), An International Survey of the Energy Service Company (ESCO) Industry. Energy Policy, 33(5), 691-704;

[22] Vine, E., Nakagami, H. and Murakoshi, C. (1999), The Evolution of the US Energy Service Company (ESCO) Industry: from ESCO to Super ESCO. Energy, 24(6), 479-492;

[23] Vine, E., Murakoshi, C. and Nakagami, H. (1998), International ESCO Business Opportunities and Challenges: A Japanese Case Study. Energy, 23(6), 439-447;

[24] Yilmaz, B. and Dagdeviren, M. (2011), A Combined Approach for Equipment Selection: F-PROMETHEE Method and Zero-One Goal Programming. Expert Systems with Applications, 38, 11641-11650;

[25] Zakernia, M., Ghaderi, F. and Piltan, M. (2010), Optimal Portfolio Selection between Different Kinds of Renewable Energy Sources. In Montreal 2010: World Energy Council. 